\title{
The influence of tetraethoxysilane sol preparation on the electrospinning of silica nanofibers
}

Jozefien Geltmeyer, Jonathan De Roo, Freya Van Den Broeck, José Martins, Klaartje De Buysser, Karen De Clerck

Abstract: The critical parameters determining the electrospinning of silica nanofibers starting from tetraethoxysilane sols are reported. By controlling the reaction conditions, the rheological properties of the sol allowed for electrospinning without the need of the addition of an organic polymer. This permits to skip the polymer removal step, which is deleterious to the fibers and an economic and ecological inconvenience. The effects on the electrospinning process of the viscosity of the sol, the concentration of ethanol, the degree of crosslinking and the size of the colloidal species was studied in-depth with ATR-FTIR, ${ }^{29}$ Si NMR, ${ }^{1} H$ NMR and DLS. Moreover, to separate the contributions of the different parameters three different set-ups for sol preparation were used. An optimum amount of $9 \mathrm{~mol} \mathrm{~L}^{-1}$ ethanol for electrospinning was determined. In addition, the optimum degree of crosslinking and size of colloidal particles, approximately $3.5-7 \mathrm{~nm}$, was found for stable electrospinning and for producing uniform, beadless nanofibers which were stable in time. The optimum viscosity range is in between 100 and $200 \mathrm{mPa}$ s, which is in line with previous work. Using these optimum conditions continuous electrospinning was carried out during 3 hours resulting in large flexible silica nanofibrous membranes.

Keywords: electrospinning, sol-gel, NMR, silica, nanofibers

\section{Introduction}

The interest in electrospinning of ceramic nanofibers has grown drastically the last years [1-4]. Due to the small fiber diameters, nanofibrous nonwovens have a very high specific surface area, small pore size and high porosity. Ceramic materials are typically hard and inert and thus well known for their high thermal and chemical resistance. The combination of these unique properties makes these nanofibers advantageous for various applications such as fuel cells [5], solar cells [6], catalysis [7], filtration [8-10], sensors [11], etc. Electrospinning is a simple and versatile technique for the production of polymer and ceramic nanofibers [12-16]. Using electrostatic forces continuous nanofibers can be obtained having controllable compositions and controllable diameters below $500 \mathrm{~nm}$. The production of polymeric nanofibers is straightforward since a polymer is simply dissolved in an appropriate solvent. The production of ceramic nanofibers requires more elaborate procedures for precursor solution synthesis that are often based on sol-gel chemistry. The sol-gel process is a well-known process in materials science [2022]. It is used for the deposition of thin films, the production of dense ceramic materials, powders, aerogels, ceramic fibers, etc. In the sol-gel process, a three dimensional network is formed via hydrolysis and subsequent condensation of an alkoxide precursor [20]. 
The combination of electrospinning and the sol-gel technique is relatively recent but has already been used to obtain ceramic nanofibers with various compositions such as $\mathrm{SiO}_{2}$ [23-25], $\mathrm{TiO}_{2}$ [26,27], $\mathrm{Al}_{2} \mathrm{O}_{3}$ [28], $\mathrm{ZrO}_{2}$ [29,30], etc. So far, the most common technique to obtain ceramic nanofibers is the electrospinning of solutions containing a sol-gel precursor and an organic polymer. The polymer is added to control the rheological properties of the solution. Afterwards, this polymer is removed via a thermal treatment to obtain pure ceramic nanofibers. However, removing the polymer may result in poor mechanical properties and eventually loss of the materials coherence [31]. Electrospinning without the addition of a polymer is thus preferred and in previous work we have already shown that this is feasible [32]. Uniform silica nanofibers can be produced in a stable and reproducible manner. A key prerequisite to obtain reproducible electrospun nanofibrous nonwovens is the presence of a stable Taylor cone in time. The viscosity of the sol has a big influence on the electrospinning stability and on the diameters of the resulting nanofibers. The most stable electrospinning of TEOS sols was obtained in the range 120-200 $\mathrm{mPa}$ s. It was established that also the preparation procedure of the sol influences the electrospinning process. This indicates that other critical parameters, such as the concentration of ethanol, the size of colloidal species and the degree of crosslinking, influence the viscosity and thus the stability of the electrospinning process (Figure 1).

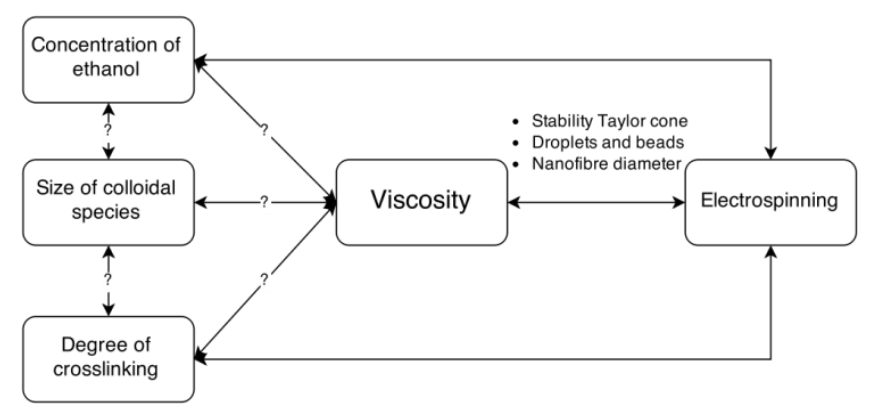

Figure 1: Schematic overview of the sol parameters influencing the viscosity and the electrospinning process

To clearly separate the contributions of the critical parameters, three different sol preparation setups are compared in this paper (Figure 2). An open system was used in previous work and is the most practical set-up. However, in this set-up the influence of the degree of crosslinking or the concentration of ethanol on the electrospinning process cannot be separated. A closed system with a Liebig cooler is a distillation set-up, which allows to observe the evaporation of ethanol during sol preparation. This method is similar to the open system since the crosslinking and ethanol evaporation occur at the same time, which results in an increased sol viscosity. A closed system with a reflux condenser, Allihn set-up, keeps the ethanol in the system. Ethanol is removed afterwards via a rotary evaporator to obtain a viscous sol necessary for electrospinning. In this way both parameters, degree of crosslinking and ethanol concentration, can be examined separately. 


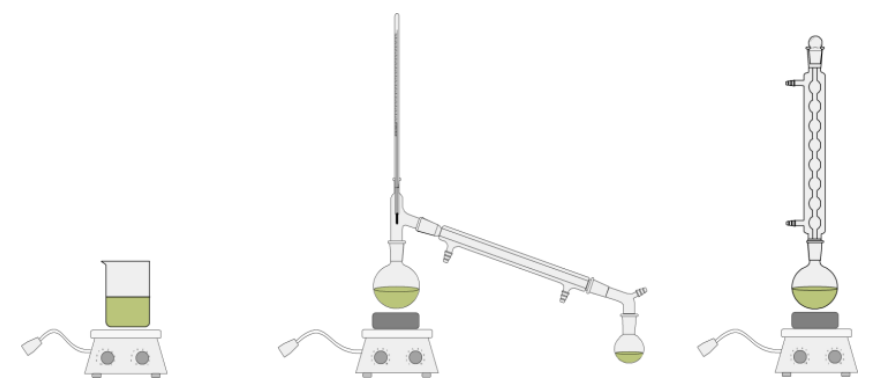

Figure 2: Open system (left), Liebig set-up (center) and Allihn set-up (right)

To evaluate these different critical parameters multiple characterization techniques are used, namely ${ }^{1} \mathrm{H}$ NMR, ${ }^{29} \mathrm{Si}$ NMR, ATR-FTIR and DLS. The first parameter that is characterized is the concentration of ethanol evaporated out of the sols and the concentration of ethanol still present in the sols after evaporation. The first will be determined using the Liebig set-up, the latter will be determined via ${ }^{1} \mathrm{H}$ NMR. Next, the degree of crosslinking of the sols will be studied in-depth via ATR-FTIR and ${ }^{29} \mathrm{Si}$ NMR. Multiple research groups [33-40] have performed ${ }^{29} \mathrm{Si}$ NMR studies on sols with varying compositions and $\mathrm{r}$ ratios, with $\mathrm{r}$ the $\mathrm{H}_{2} \mathrm{O} / \mathrm{Si}$ molar ratio. Brinker et al [33] conducted ${ }^{29} \mathrm{Si}$ NMR measurements on silica sols for conventional fiber drawing. Malay et al [39] and Sadasivan et al [40] combined ${ }^{29} \mathrm{Si}$ NMR and DLS for a detailed study of the effect of the solvent on silica synthesis. In this paper the size of colloidal species in the sols will be evaluated via DLS. These techniques thus show to be very promising for characterization. An indepth study, however, of the TEOS sols used for electrospinning is still missing. By combining three different set-ups, DLS, ${ }^{29} \mathrm{Si}$ NMR, ${ }^{1} \mathrm{H}$ NMR and ATR-FTIR the influence of the critical parameters on the viscosity and thus the electrospinning process is thoroughly characterized. A breakthrough in the production of silica nanofibers without polymer addition can be obtained with the results of this research.

\section{Materials and Methods}

The alkoxide precursor tetraethoxysilane (TEOS, reagent grade 98\%) was supplied by SigmaAldrich and used as received. The solvent, absolute ethanol, and catalyst, hydrochloric acid $(\mathrm{HCl}, 37 \%)$ were also obtained from Sigma-Aldrich.

Three different systems, one open and two closed, were used for the preparation of the sols, Figure 2. A detailed description of the preparation procedure of sols via the open system can be found in Geltmeyer et al [32]. The first steps of the preparation procedure are similar for all setups. All sols are prepared from a mixture of TEOS, ethanol, distilled water and $\mathrm{HCl}$ with a molar ratio of respectively 1:2:2:0.01. Firstly, TEOS and ethanol are mixed. Secondly, aqueous $\mathrm{HCl}$ is added to the solution under vigorous stirring with a magnetic stir bar. After completion of the hydrolysis reactions (exothermic) the sols are heated at $80^{\circ} \mathrm{C}$.

In the open system, sols were heated and stirred in a beaker, in contact with the atmosphere. In the Liebig set-up, evaporated ethanol is condensed via a Liebig cooler and collected in a round bottom flask. The evaporation of ethanol is monitored by weighing the condensed ethanol after 
fixed time periods. The solution is left for reaction until the desired viscosity is reached. Finally, the solution is cooled down to room temperature. In the Allihn set-up, ethanol is refluxing and cannot escape from the system. The solution is left for reaction for fixed time periods of $30 \mathrm{~min}$, $2 \mathrm{~h}, 6 \mathrm{~h}, 12 \mathrm{~h}, 24 \mathrm{~h}$ and $48 \mathrm{~h}$. Next, a rotary evaporator is used to evaporate ethanol until a desired viscosity is reached. Samples prepared via the open system, via the Liebig set-up, via the Allihn set-up before ethanol evaporation or via the Allihn set-up after ethanol evaporation will be denoted respectively with the letters $\mathrm{O}, \mathrm{L}, \mathrm{A}$ or Ae followed by the viscosity of the sol or the reaction time.

The viscosity of the solutions was measured using a Brookfield viscometer LVDV-II. A mononozzle electrospinning set-up was used to obtain the nanofibrous structures. The sols were loaded in a 20-mL syringe equipped with a needle with an inner diameter of $1.024 \mathrm{~mm}$. A Glassman High Voltage Series EH 30P3 was used to apply a voltage of $22.5 \mathrm{kV}$ and the flow rate was fixed at $1 \mathrm{~mL} \mathrm{~h}^{-1}$ with a syringe KD Scientific Pump Series 100. The tip-to-collector distance was fixed at $15 \mathrm{~cm}$. The nanofibers were collected on a grounded aluminum foil. All experiments were performed at room temperature and room humidity. The stability of the electrospinning process was evaluated by visually evaluating the stability of the Taylor cone in time and by verifying the absence of droplets and beads on the SEM images.

For ${ }^{29} \mathrm{Si}$ NMR, the sols were diluted with $10 \% \mathrm{D}_{2} \mathrm{O}$ and $600 \mu \mathrm{l}$ was put in a NMR tube. Measurements were recorded on a Bruker Avance III Spectrometer operating at a ${ }^{1} \mathrm{H}$ frequency of $500.13 \mathrm{MHz}, \mathrm{a}^{29} \mathrm{Si}$ frequency of $99.36 \mathrm{MHz}$ and equipped with a BBI-Z probe. The sample temperature was set to $298.2 \mathrm{~K}$. One dimensional (1D) ${ }^{29} \mathrm{Si}$ quantitative spectra were acquired using a zggpseig pulse sequence, this sequence was chosen in order to maximize signal intensities and avoid residual signal from the glass of the NMR tube. Throughout all measurements, 29840 data points were sampled with the spectral width set to $450 \mathrm{ppm}$ around an o1 of $0 \mathrm{ppm}$ and a relaxation delay of $60 \mathrm{sec}$. The number of scans was set to 205 and the number of dummy scans to 4 . This results in a total measuring time of $3.5 \mathrm{~h}$, which gave good signal to noise rate without giving the samples sufficient time to gelate.

For Dynamic Light Scattering (DLS) a Malvern Nano ZS was used in backscattering mode $\left(173^{\circ}\right)$. An Attenuated Total Reflectance Fourier Transform Infrared (ATR-FTIR) spectrometer from Thermo Scientific was used to record the IR spectra of both the sols and the nanofibers. The spectra were recorded in the range $4000-400 \mathrm{~cm}^{-1}$ with a resolution of $4 \mathrm{~cm}^{-1}, 32$ scans were taken for each experiment. Fiber morphology and fiber diameters were examined using a scanning electron microscope (FEI Quanta $200 \mathrm{~F}$ ) at an accelerating voltage of $20 \mathrm{kV}$. The samples were coated prior to SEM analysis using a sputter coater (Emitech SC7620, coating with $\mathrm{Au}$ ). The nanofiber diameters were measured using Olympus Cell $\mathrm{D}$ software by taking an average of 50 measurements. 


\section{Results and discussion}

\section{Characterization of silica sols}

The influence of the viscosity on the electrospinning process has been researched [32], but a more in-depth characterization of the other critical parameters: amount of ethanol, size of colloidal species and degree of crosslinking is missing (Figure 1). To clearly separate the contributions of the critical parameters, three different sol preparation set-ups are compared (Figure 2). An overview of the advantages and disadvantages of the different set-ups is given in Table 1.

Table 1: advantages and disadvantages of the different set-ups

\begin{tabular}{|c|c|c|}
\hline Open system & $\begin{array}{l}\text { Closed systems } \\
\text { Liebig set-up }\end{array}$ & Allihn set-up \\
\hline $\begin{array}{l}\text { + fast } \\
\text { - no control } \\
\text { - evaporation of ethanol and } \\
\text { crosslinking at same time } \\
+ \text { simple and practical }\end{array}$ & $\begin{array}{l}+ \text { fast } \\
+ \text { control } \\
\text { - evaporation of ethanol and } \\
\text { crosslinking at same time } \\
+ \text { similar to open system }\end{array}$ & $\begin{array}{l}\text { - slow } \\
+ \text { control } \\
+ \text { separate evaporation of } \\
\text { ethanol and crosslinking } \\
\text { - Second step: evaporation of } \\
\text { ethanol }\end{array}$ \\
\hline
\end{tabular}

\subsection{Degree of crosslinking}

Via ATR-FTIR and ${ }^{29} \mathrm{Si}$ NMR spectroscopy the degree of crosslinking in the sols and the influence on viscosity is investigated. First of all, the reproducibility of all sols via all three setups was confirmed via both ATR-FTIR and ${ }^{29}$ Si NMR (data not shown).

ATR-FTIR spectra of sols prepared in the open system with varying viscosities are compared, illustrated in Figure 3 for the $10 \mathrm{mPa} s$ and the $170 \mathrm{mPa} s$ samples. An overview of the assignment of the different peaks is given in Table 2 [41-44]. Clear differences in peak height can be seen for the sols with different viscosities. At $431 \mathrm{~cm}^{-1}$, corresponding with Si-O-Si bend, an increase in peak height is seen with increasing viscosity. This gives an indication of increased crosslinking. The differences in peak heights in the region $1200-700 \mathrm{~cm}^{-1}$ can be ascribed to a different degree of crosslinking or to a difference in ethanol concentration. Indeed, the peaks of $\mathrm{Si}-\mathrm{O}-\mathrm{Si}$ at $1076 \mathrm{~cm}^{-1}$ and of C-C-O at $1044 \mathrm{~cm}^{-1}$ overlap. Additionally, the broad peak at 3324 $\mathrm{cm}^{-1}$ corresponding with $\mathrm{OH}$ stretch decreases with increasing viscosity. This might be attributed to the evaporation of ethanol or by the condensation of $\mathrm{Si}-\mathrm{OH}$ in $\mathrm{Si}-\mathrm{O}-\mathrm{Si}$, and thus higher crosslinking. ATR-FTIR hints at an increased crosslinking with increasing viscosity, but other techniques are necessary to draw unambiguous conclusions.

Table 2: Peak assignment in ATR-FTIR spectra

\section{Wavenumber $\left(\mathrm{cm}^{-1}\right)$ Assignment}

\begin{tabular}{ll}
\hline $\mathbf{3 3 2 4}$ & $\mathrm{OH}$ stretch \\
$\mathbf{2 9 7 4}$ & $\mathrm{CH}_{3} \mathrm{CH}_{2}$ \\
\hline
\end{tabular}




\begin{tabular}{ll}
\hline $\mathbf{2 8 9 4}$ & $\mathrm{CH}_{3} \mathrm{CH}_{2}$ \\
$\mathbf{1 3 8 3}$ & $\mathrm{CH}_{3}$ bend/OH bend \\
$\mathbf{1 1 5 4}$ & Si-O-C/C-O-C/CH \\
$\mathbf{1 0 7 6}$ & Si-O-Si Asymm stretch \\
$\mathbf{1 0 4 4}$ & C-C-O Asymm stretch \\
$\mathbf{9 6 6}$ & Silanol Si-OH stretch \\
$\mathbf{8 8 0}$ & C-C-O Symm stretch \\
$\mathbf{7 9 5}$ & Si-O-Si Symm stretch \\
$\mathbf{5 8 2}$ & OH out of plane bend \\
$\mathbf{4 3 1}$ & Si-O-Si bend \\
\hline
\end{tabular}

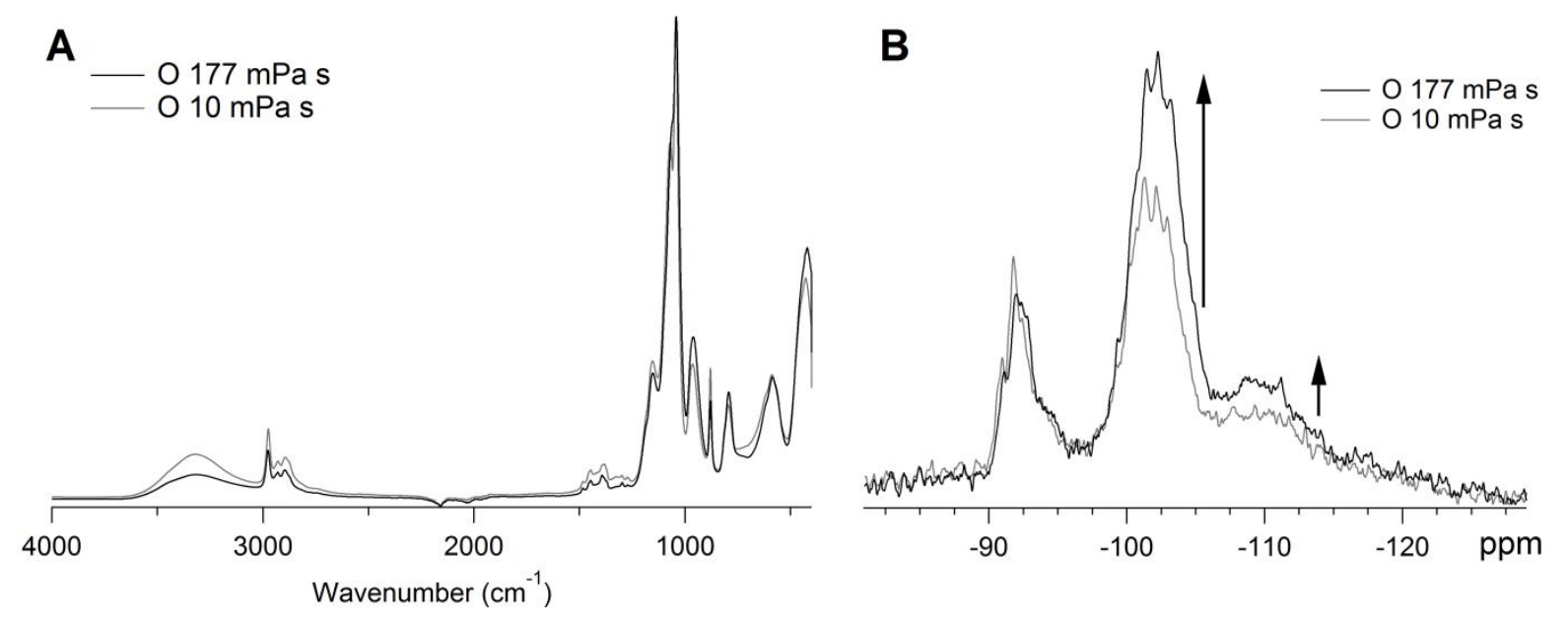

Figure 3: ATR-FTIR (A) and ${ }^{29} \mathrm{Si}$ NMR (B) spectra of sols with a viscosity of 10 an $177 \mathrm{mPa}$ s prepared in the open system Therefore, the same sols were investigated via solution ${ }^{29} \mathrm{Si} N \mathrm{NR}$, see Figure $3 \mathrm{~B} . \mathrm{Q}^{\mathrm{n}}$ notation is commonly used in ${ }^{29} \mathrm{Si} \mathrm{NMR}$ to present the structure of the building units. Q represents a silicon atom bonded to four oxygen atoms forming a tetrahedron, the superscript $\mathrm{n}$ represents the connectivity (the number of other $\mathrm{Q}$ units attached to the studied $\mathrm{SiO}_{4}$ tetrahedron). The spectra of both sols show resonances in three different regions: $\mathrm{Q}^{2}$ species: $-90 \mathrm{ppm}$ to $-97 \mathrm{ppm}, \mathrm{Q}^{3}$ species: $-98 \mathrm{ppm}$ to $-105 \mathrm{ppm}$ and $\mathrm{Q}^{4}$ species: -105 to $-115 \mathrm{ppm}$. For detailed assignments of the different $\mathrm{Q}$ species we refer to literature [45-47]. The amount of $\mathrm{Q}^{3}$ and $\mathrm{Q}^{4}$ species increases with an increased sol viscosity, thus confirming the increased degree of crosslinking with increasing viscosity. Figure 4A illustrates the trend for the Liebig set-up to be similar to the open system. Again a higher viscosity leads to more $\mathrm{Q}^{3}$ and $\mathrm{Q}^{4}$ species.

It is observed that when a sol with a too high viscosity is diluted to an optimum viscosity the electrospinning results are different than for sols that have the optimum viscosity from the beginning [32]. The spectrum of a sample with a reference viscosity of $158 \mathrm{mPa}$ (stable region) is compared to a sample with a viscosity of $682 \mathrm{mPa}$ s diluted to this reference viscosity, Figure 4B. The diluted sample has more $\mathrm{Q}^{4}$ and therefore a higher degree of crosslinking. Therefore, we 
can conclude that a dilution with ethanol can decrease the viscosity but the crosslinking of the sols remains intact.
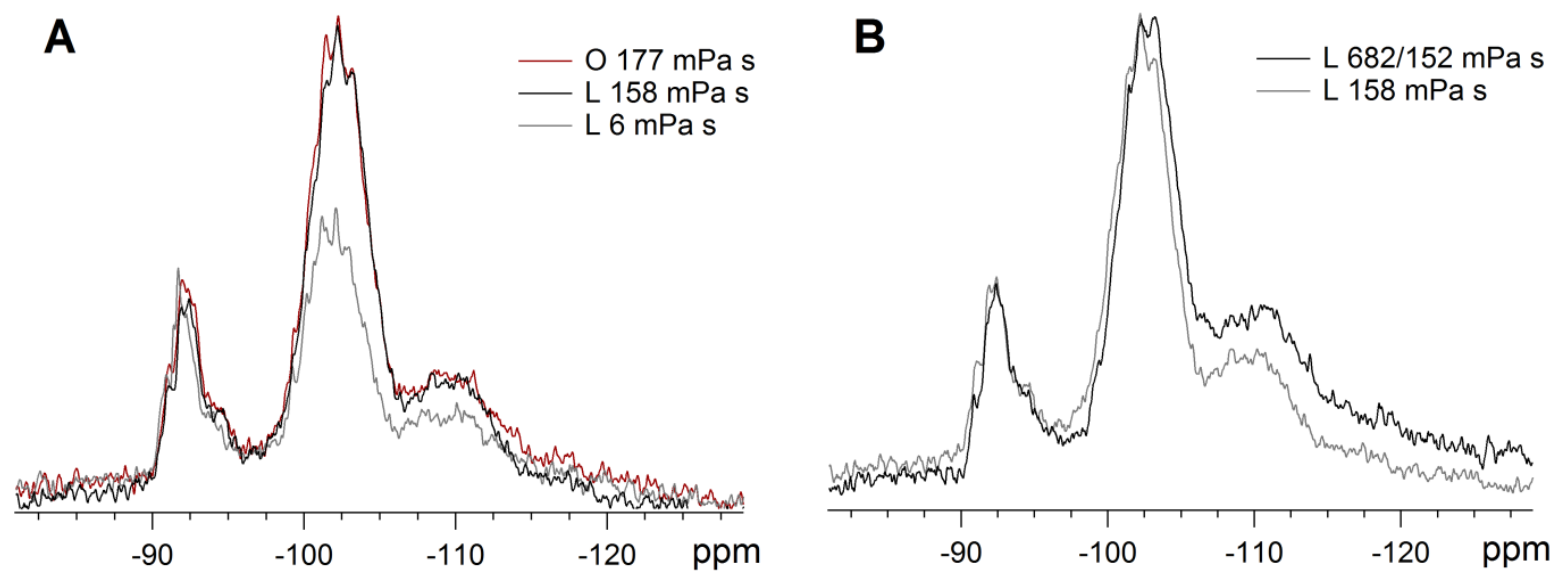

Figure 4: ${ }^{29} \mathrm{Si}$ NMR spectra of sols prepared in the open system and Liebig set-up (A), and ${ }^{29} \mathrm{Si}$ NMR spectra of a diluted and a undiluted sol prepared in the Liebig set-up (B)

ATR-FTIR provides more reliable information for the sols prepared via the Allihn set-up since all samples have the same concentration of ethanol. With an increasing reaction time the peaks at $980 \mathrm{~cm}^{-1}$ (Si-OH bonds, Table 2) show a clear decrease, which may be ascribed to an increasing degree of crosslinking, Figure 5A. A complementary characterization of the degree of crosslinking and the $\mathrm{Q}$ species present in the sols is executed via ${ }^{29} \mathrm{Si}$ NMR. When comparing sols prepared in the Allihn set-up with increasing reaction times important changes in crosslinking degree are determined (Figure 5B). Firstly, the amount of $\mathrm{Q}^{2}$ species decreases drastically when the reaction time is increased from $30 \mathrm{~min}$ to $24 \mathrm{~h}$. Secondly, the amount of $\mathrm{Q}^{3}$ species stays practically constant, but a shift in the $\mathrm{Q}^{3}$ peak is seen. With increasing reaction time different $\mathrm{Q}^{3}$ species seem to be formed. Additionally, the amount of $\mathrm{Q}^{4}$ increases as well. In conclusion, the increased crosslinking degree with increased viscosity or increased reaction time is confirmed for all set-ups. The influence hereof on the electrospinning process and resulting nanofibers is discussed later. 

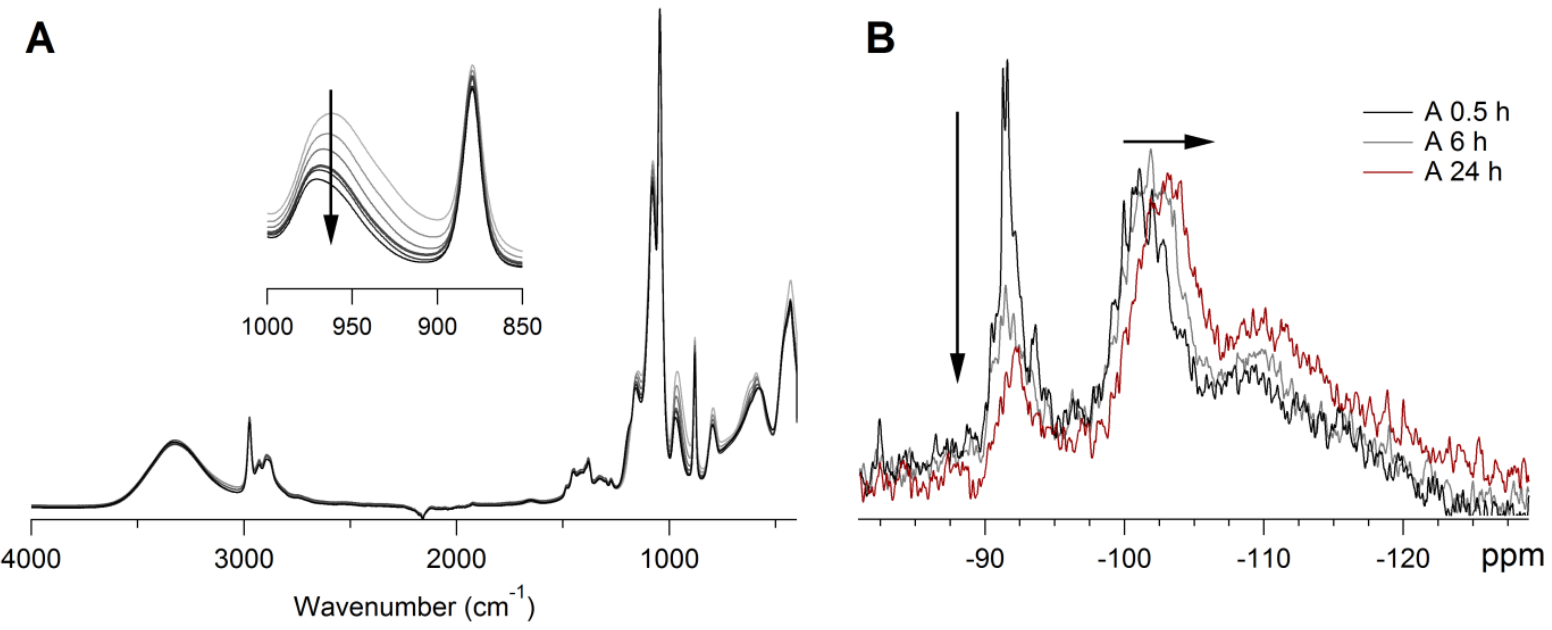

Figure 5: ATR-FTIR spectra of sols prepared in the Allihn set-up with increasing reaction times (A), ${ }^{29} \mathrm{Si}$ NMR spectra of Allihn sols with increasing reaction time (B)

\subsection{Evaporation of ethanol.}

Both the amount of solvent evaporated as the amount of ethanol still present in the sols after evaporation are determined. When preparing sols via the open system it was clearly visible that the volume of the solution diminishes, which is attributable to the evaporation of the solvent. Using the Liebig set-up the evaporated solvent was collected and followed in time. The amount of ethanol still present in the sols after evaporation of the solvent was measured via ${ }^{1} \mathrm{H}$ NMR for sols prepared via all three set-ups.

Both the reaction time as the amount of solvent evaporated were studied as a function of the viscosity of the sols prepared in the Liebig set-up (Figure 7). A slow increase in viscosity is seen with increasing reaction time, followed by a very sharp increase, when heating at $80^{\circ} \mathrm{C}$ is continued, once a viscosity of around $180 \mathrm{mPa} s$ is attained. Together with this, evaporation of the solvent commences already from the start of the reaction with an almost linear increase as a function of reaction time. However, once a reaction time of $150 \mathrm{~min}$ or a viscosity around 80 $\mathrm{mPa} s$ is attained the evaporation of solvent decelerates. The initial stage of the viscosity increase of the sols can thus be attributed to the evaporation of ethanol. Once a critical amount of ethanol is evaporated and ethanol evaporation stagnates, further increases in sol viscosity might be attributed to crosslinking. To obtain a sol with an optimum viscosity for electrospinning the amount of solvent evaporated has to be $37 \pm 1 \mathrm{~g}$, if started with a $\pm 72 \mathrm{~mL}$ solution.

Using the Allihn set-up it was possible to keep the ethanol in the system. Different reaction times of the sols were evaluated, namely $0.5 \mathrm{~h}, 2 \mathrm{~h}, 6 \mathrm{~h}, 12 \mathrm{~h}, 24 \mathrm{~h}$ and $48 \mathrm{~h}$. For these samples a constant viscosity of 2-3 $\mathrm{mPa} s$ was measured for all sols. To obtain electrospinnable sols from the Allihn set-up, the ethanol has to be evaporated using a rotary evaporator. To obtain viscous sols a certain, critical, amount of ethanol thus has to be evaporated. 


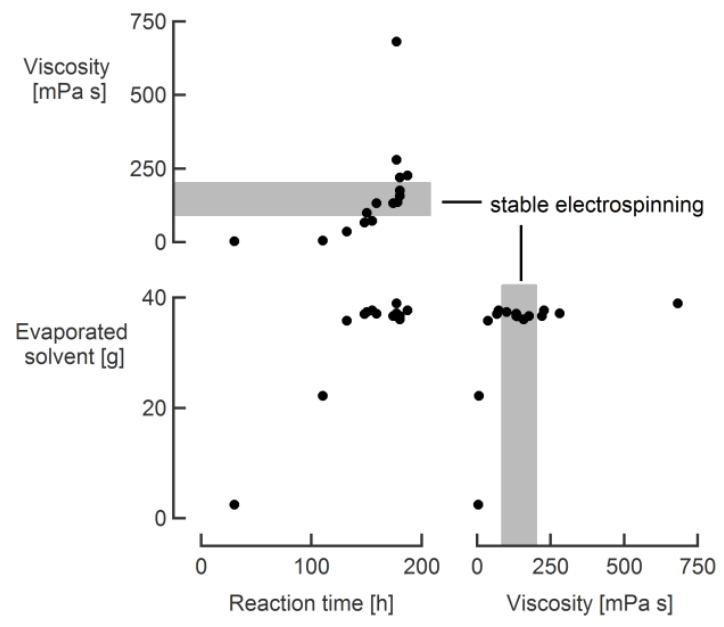

Figure 6: Viscosity increase Liebig sols as a function of reaction time (upper) and amount of solvent evaporated as a function of reaction time and viscosity of the sols (lower)

The amount of ethanol in the sols prepared via the three different systems was determined via ${ }^{1} \mathrm{H}$ NMR. The sols prepared via the Allihn set-up have a constant amount of ethanol; $13.3 \pm 0.2 \mathrm{~mol}$ $\mathrm{L}^{-1}$, which is in line with the expectations since ethanol stays in the system. In addition, a sol prepared with the Liebig set-up with a reaction time of $30 \mathrm{~min}$ also shows an ethanol concentration of $13.4 \mathrm{~mol} \mathrm{~L}-1$. This is expected since almost no ethanol is evaporated after 30 min. The electrospinnable sols, which includes sols prepared via the open system, Liebig set-up and Allihn set-up after evaporation via the rotary evaporator, all had a concentration of ethanol around $9 \mathrm{~mol} \mathrm{~L}^{-1}$. This value thus seems the natural threshold of the open system and the Liebig set-up, and is found ideal for electrospinning. To conclude, an optimum amount of solvent has to be evaporated to obtain viscous electrospinnable sols. Moreover, for all three systems the same threshold concentration of ethanol, $9 \mathrm{~mol} \mathrm{~L}^{-1}$, was found to obtain electrospinnable sols.

\subsection{Size of colloidal species in the sols.}

Additional information on the size of colloidal species in the sols is obtained using DLS. A clear growth in colloidal particle size with increasing reaction time and viscosity is seen for the samples prepared with the Liebig set-up, Figure 7A. These results are in line with the general theory of polymerization of silica proposed by Iler [20,47]. In acidic solutions particles are formed, which then aggregate into three dimensional networks which leads to a viscosity increase. According to theory, the particle size increases with increasing $\mathrm{pH}$. The evaporation of the solvent, or more correctly the azeotrope ethanol 95,63 w\% - water 4,37 w\% (contains $\mathrm{HCl}$ ) leads to an increased $\mathrm{pH}$ and results in colloidal growth.

Also the particle size of sols prepared via the Allihn condenser was determined via DLS, see Figure 7B. It is clear that the particles grow with time. The particle size increases from around $2,5 \mathrm{~nm}$ for a sol with a reaction time of 30 min to a particle size of around $7 \mathrm{~nm}$ for the sol with a reaction time of $48 \mathrm{~h}$. Both the degree of crosslinking (see above) and the size of the particles 
increase with reaction time. Moreover, the size of the colloidal particles before and after ethanol evaporation remains largely unaltered (Figure 7B). We infer that there is little or no influence of ethanol evaporation on the final sols.
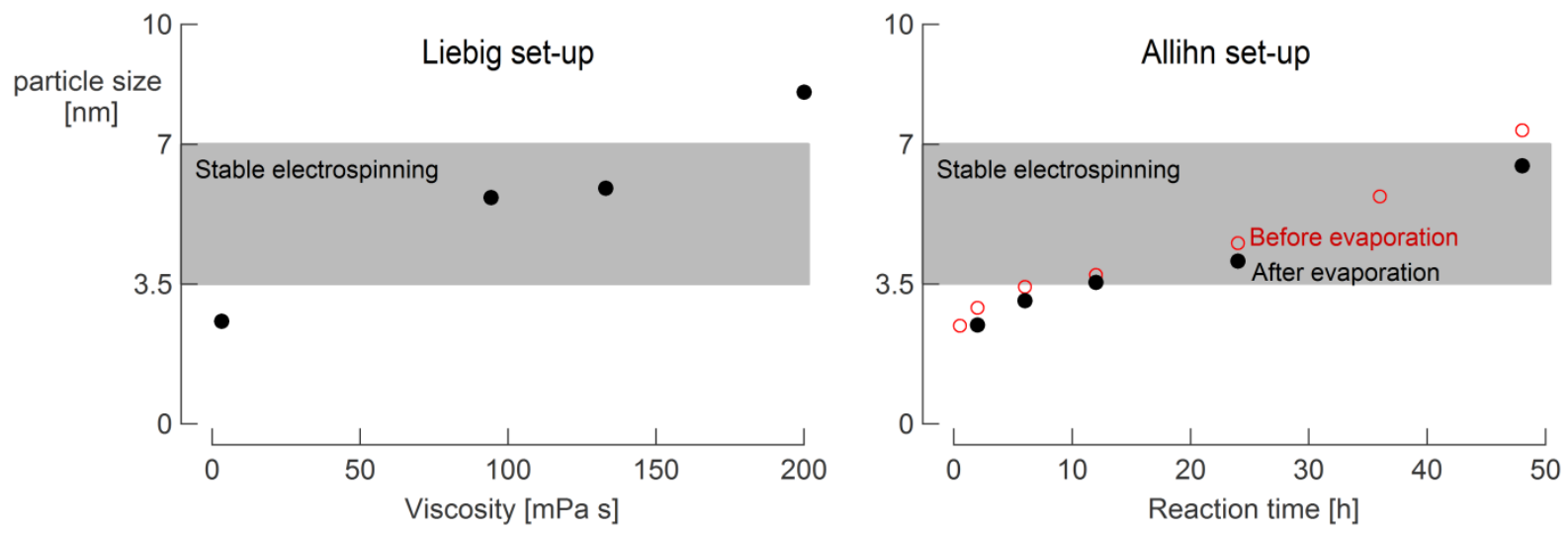

Figure 7: Colloidal particle size in the sols prepared via the Liebig set-up (left) and Allihn set-up (right)

\section{Influence of critical parameters on morphology and stability in time of the nanofibers}

A profound view on the degree of crosslinking, size of the colloidal species and amount of ethanol in the sols prepared via three different set-ups was obtained. All of these parameters show to have an influence on the electrospinning process. An overview on the electrospinning stability of the sols prepared with the open system, Liebig set-up and Allihn set-up is provided in Table 3. For the Allihn set-up we make a distinction between the sols before $(\mathrm{A} 1, \mathrm{~A} 2, \ldots)$ and after (A1e, A2e, ...) evaporation of ethanol. Based on their electrospinning stability and the resulting nanofibers the sols are divided in four different zones: --, ++, + and -. Figure 8 gives an overview of the links between the critical parameters and their optimum values.

Table 3: Electrospinning stability of sols prepared via the Allihn and Liebig set-up

\begin{tabular}{|c|c|c|c|c|c|c|c|c|c|c|c|c|}
\hline \multicolumn{7}{|c|}{ Allihn set-up } & \multicolumn{3}{|c|}{ Liebig set-up } & \multicolumn{3}{|c|}{ Open system } \\
\hline & $\begin{array}{l}\text { Reaction } \\
\text { time (h) }\end{array}$ & $\mathbf{E S}^{+}$ & & $\begin{array}{l}\text { Reaction } \\
\text { time (h) }\end{array}$ & $\boldsymbol{\eta}^{*}$ & $\mathbf{E S}^{+}$ & & $\eta^{*}$ & $\mathbf{E S}^{+}$ & & $\eta^{*}$ & $\mathbf{E S}^{+}$ \\
\hline A1 & 0.5 & -- & Ale & 0.5 & 3 & -- & L1 & 3 & -- & $\mathrm{O} 1$ & 17 & -- \\
\hline $\mathrm{A} 2$ & 2 & -- & $\mathrm{A} 2 \mathrm{e}$ & 2 & 37 & -- & L2 & 36 & -- & $\mathrm{O} 2$ & 65 & - \\
\hline A3 & 2 & -- & $\mathrm{A} 3 \mathrm{e}$ & 2 & 61 & + & L3 & 73 & - & $\mathrm{O} 3$ & 82 & - \\
\hline A4 & 2 & -- & $\mathrm{A} 4 \mathrm{e}$ & 2 & 122 & + & $\mathrm{L} 4$ & 100 & ++ & $\mathrm{O} 4$ & 118 & ++ \\
\hline A5 & 6 & -- & $\mathrm{A} 5 \mathrm{e}$ & 6 & 59 & + & L5 & 116 & ++ & $\mathrm{O5}$ & 136 & ++ \\
\hline A6 & 6 & -- & A6e & 6 & 294 & + & L6 & 133 & ++ & O6 & 152 & ++ \\
\hline A7 & 12 & -- & A7e & 12 & 75 & ++ & L7 & 136 & ++ & $\mathrm{O} 7$ & 161 & ++ \\
\hline A8 & 12 & -- & $\mathrm{A} 8 \mathrm{e}$ & 12 & 104 & ++ & L8 & 153 & ++ & $\mathrm{O} 8$ & 183 & ++ \\
\hline A9 & 24 & -- & A9e & 24 & 50 & ++ & L9 & 158 & ++ & O9 & 198 & ++ \\
\hline A10 & 24 & -- & $\mathrm{A} 10 \mathrm{e}$ & 24 & 61 & ++ & L10 & 160 & ++ & O10 & 260 & - \\
\hline A11 & 24 & -- & A11e & 24 & 165 & ++ & L11 & 280 & - & O11 & 398 & - \\
\hline A12 & 48 & -- & $\mathrm{A} 12 \mathrm{e}$ & 48 & 102 & - & L12 & 435 & - & O12 & 981 & - \\
\hline
\end{tabular}




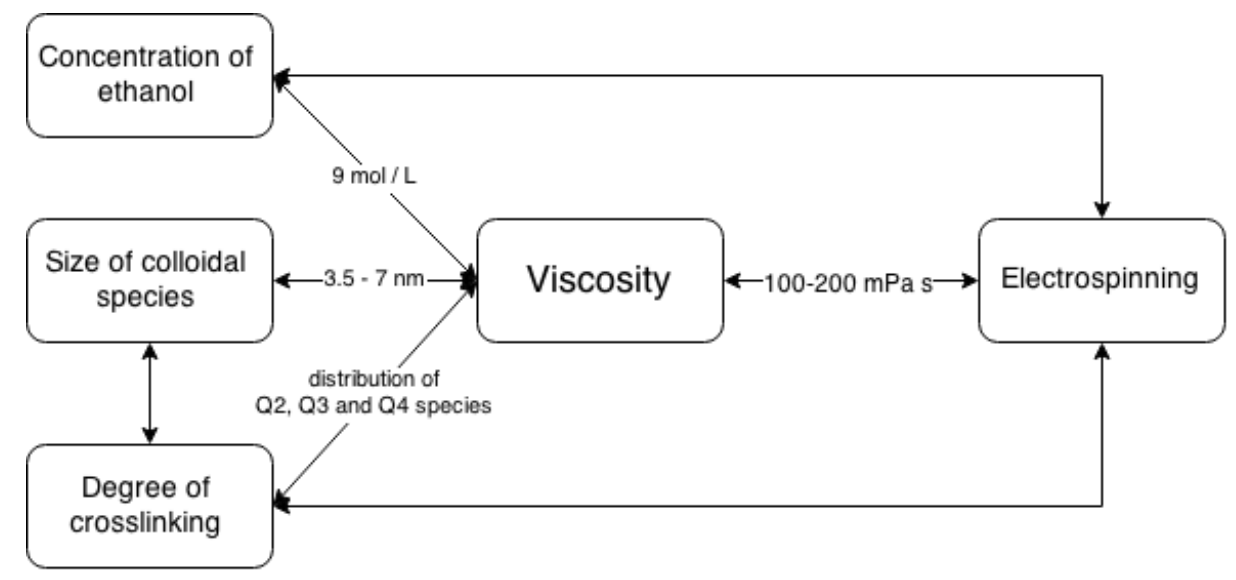

Figure 8: Parameters influencing the electrospinning process and their optimum values necessary for stable electrospinning resulting in uniform, beadless nanofibers stable in time.

The first zone, indicated with --, corresponds with sols which were not electrospinnable, only drops were deposited on the collector plate. These sols all have a viscosity that is too low, below $50 \mathrm{mPa} \mathrm{s}$, for electrospinning. Even the samples with a high degree of crosslinking (A5-A12) and sizes of colloidal species ranging in between 3 and $7 \mathrm{~nm}$, were not electrospinnable when the viscosity was too low.

A second zone, indicated by + , corresponds with a highly stable Taylor cone in time, however, further crosslinking of the nanofibers took place after deposition of the nanofibers on the collector plate (Figure $10 \mathrm{a}, \mathrm{b}$ ). These sols, A3e-A6e, prepared in the Allihn set-up with a reaction time between 2 and 6 hours have a high amount of $Q^{2}$ species and a lower amount of $Q^{3} / Q^{4}$ species compared to sols with a higher reaction time (Figure 5B). In addition, particle sizes in between 2 and $3.5 \mathrm{~nm}$ are recorded. A high amount of Q2 species and small particle sizes results thus in highly stable electrospinning. But, it results in further crosslinking of the nanofibers after deposition on the collector plate, which is negative for the stability of the fibrous web.

The sols in zone ++ had a less stable electrospinning behavior compared to zone + . However, the nanofibers showed to be stable in time, with no further crosslinking taking place. The sols prepared in the Allihn set-up with a reaction time of 12 and 24 hours, the sols prepared in the Liebig set-up and open system having a viscosity in between 100 and $200 \mathrm{mPa} \mathrm{s}$ can be classified in this zone. Via Si-NMR and DLS a higher degree of crosslinking and increased particles sizes, in between $3.5 \mathrm{~nm}$ and $7 \mathrm{~nm}$, were recorded (Figure 3B, 5B and 6). These reduced the electrospinning stability of the sols, but optimized the stability in time of the resulting nanofibers. The samples prepared via the Liebig set-up L4-L9 were electrospinnable in the same viscosity range as the sols prepared via the open system, 100-200 $\mathrm{mPa}$ s. The electrospinning of these sols resulted in uniform, beadless nanofibers (Figure $9 \mathrm{c}, \mathrm{d}$ ). The same trends are seen for 
sols prepared via the Allihn set-up (A3e-A12e), uniform and beadless nanofibers are obtained for viscosities above $100 \mathrm{mPa}$ s (Figure $10 \mathrm{e}, \mathrm{f}$ ). Due to the stable electrospinning and high stability in time of the resulting nanofibers, this zone is seen as the optimum for the electrospinning of silica nanofibers. The sols in this zone were used for further up scaling of the electrospinning process. Continuous electrospinning during 3 hours on a large rotating drum resulted in larger, uniform and flexible silica nanofibrous nonwovens, Figure 11.

In the last zone, -, electrospinning stability was less stable and beaded fibers or thicker fibers were obtained. Samples prepared in the Liebig set-up and Allihn set-up with a viscosity higher than $200 \mathrm{mPa}$ or a high degree of crosslinking and thus a particle size exceeding $7 \mathrm{~nm}$ show this reduced electrospinning stability. The electrospinning of sols with viscosities lower than 100 $\mathrm{mPa} \mathrm{s}$ (L2, L3) was also less stable, with sometimes drop formation. Moreover, the electrospinning resulted in beaded nanofibers (Figure $9 \mathrm{a}, \mathrm{b}$ ).

The viscosity has apart from the influence on the electrospinning stability, also a big influence on the resulting nanofibers and nanofiber diameters. The nanofiber diameters of Liebig and Allihn sols are evaluated and compared to the open system (Figure 12). In general, the same trends are observed for nanofibers obtained via all three set-ups. Nanofibers obtained from sols having a viscosity in between 100 and $200 \mathrm{mPa}$ s have nanofiber diameters around 200-300 nm. The nanofibers obtained from sols with viscosities below $100 \mathrm{mPa}$ s deviate more due to beads and non-uniformity's present. Above $200 \mathrm{mPa}$ s an increasing diameter is seen with an increase in viscosity. It is known that solution viscosity has a great effect on the nanofiber diameters, initiating droplet shape and jet instability $[16,48]$.

In conclusion, these results indicate that apart from the viscosity, both the degree of crosslinking and the size of colloidal particles have an influence on the electrospinning behavior. Moreover, both parameters seem to be closely related. The higher the amount of $\mathrm{Q}^{2}$ species and the smaller the colloidal particles, the more stable electrospinning is seen. But a certain degree of crosslinking is necessary to obtain uniform nanofibers which are stable after deposition. The viscosity seems to be the critical parameter determining the nanofiber diameters. Via all three set-ups it was thus possible to produce uniform, beadless nanofibers when all parameters (viscosity, degree of crosslinking, particle size and ethanol concentration) are in the appropriate border limits. Moreover, the feasibility of up scaling of the process was confirmed. 


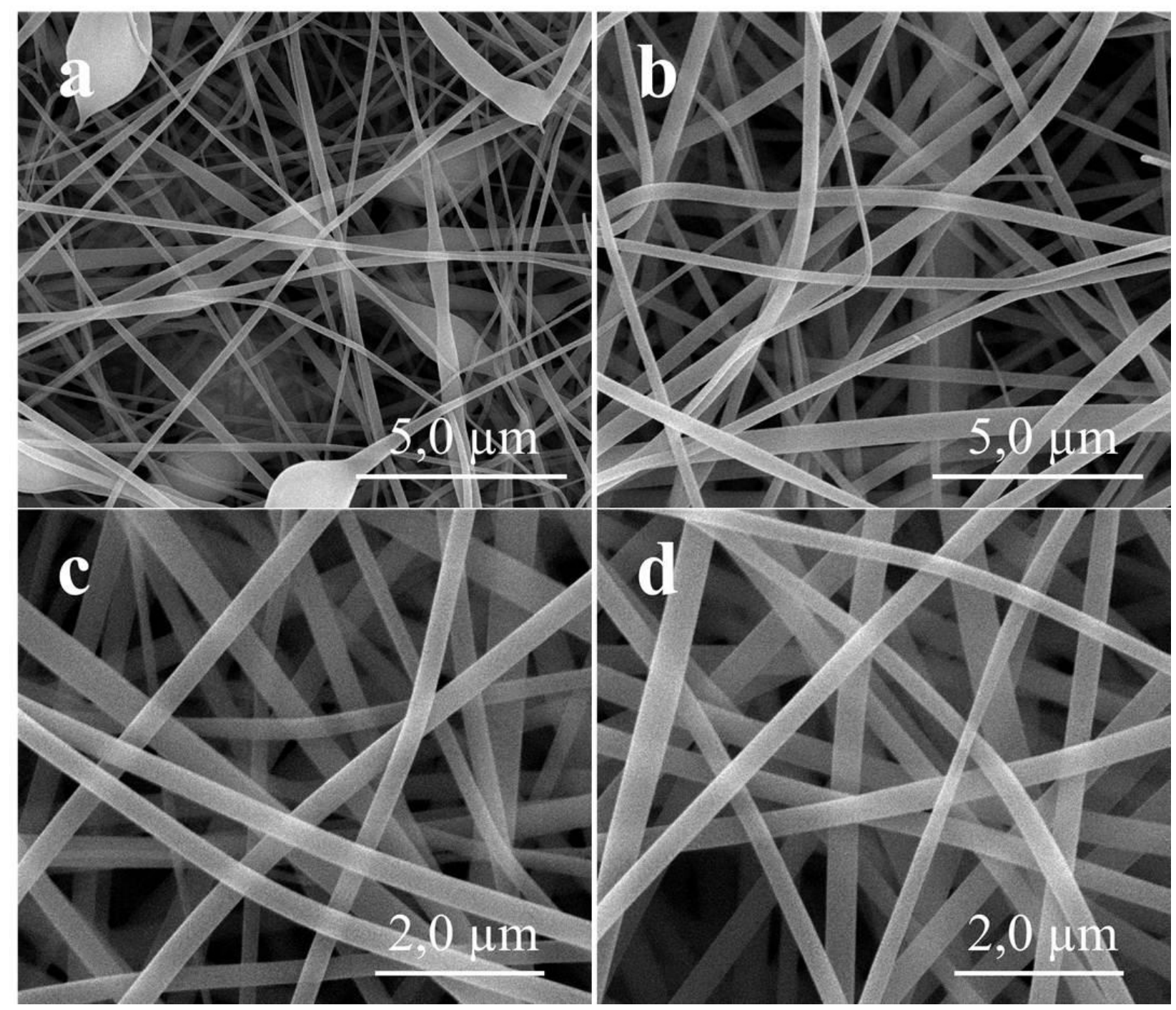

Figure 9: SEM images of nanofibers prepared from sols produced via the Liebig set-up a: 36 mPa s, b: 73 mPa s, c: 100 mPa s and d: 158 mPa s. 


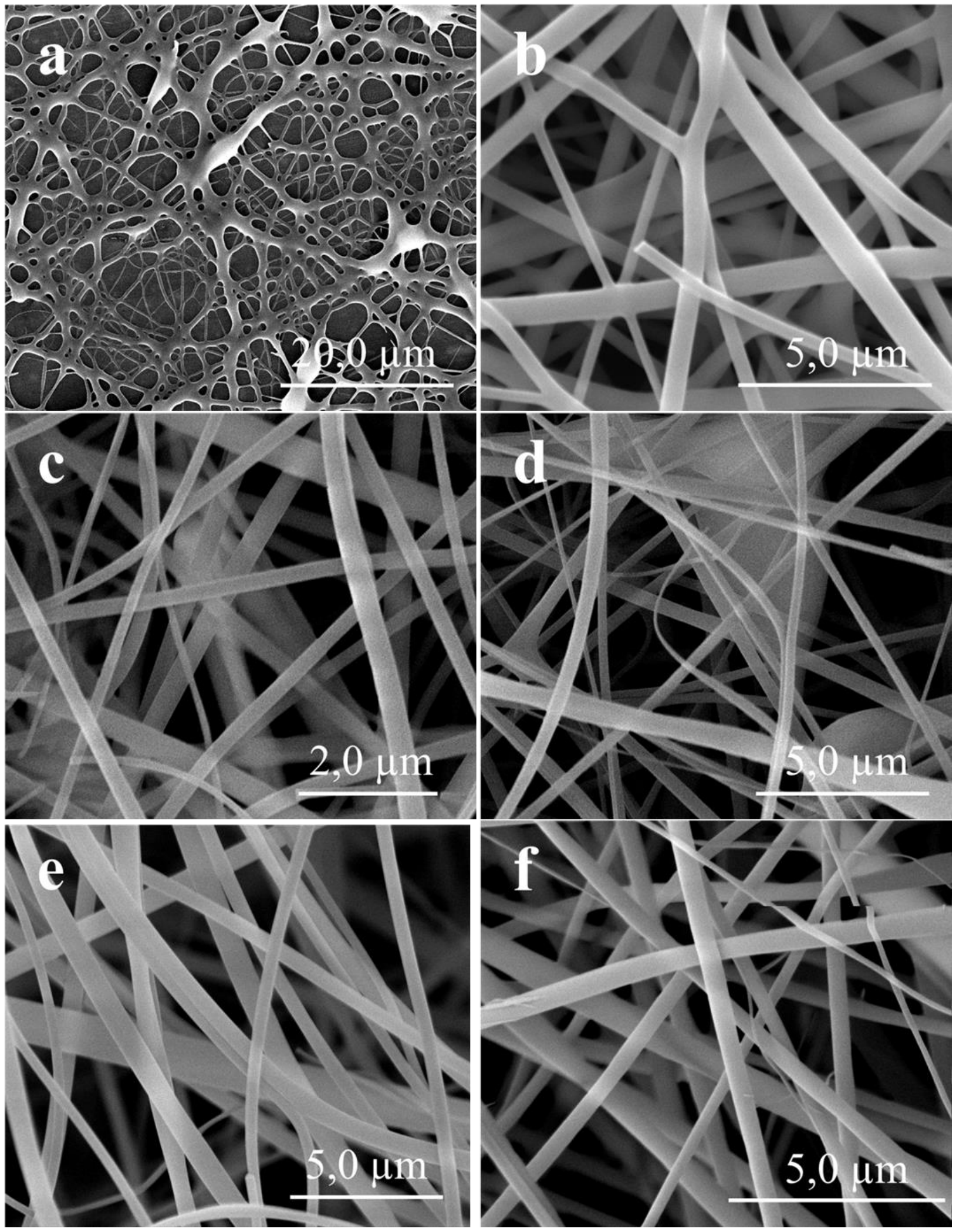

Figure 10: SEM images of nanofibers prepared from sols produced via the set-up with Allihn condenser a: $2 \mathrm{~h} 122 \mathrm{mPa}$, b: $6 \mathrm{~h} 294 \mathrm{mPa}$ s, c: $12 \mathrm{~h} 75 \mathrm{mPa}$ s, d: $24 \mathrm{~h} 47 \mathrm{mPa}$ s, e: $24 \mathrm{~h} 165 \mathrm{mPa}$ s and f: $48 \mathrm{~h} 122 \mathrm{mPa}$ s. 


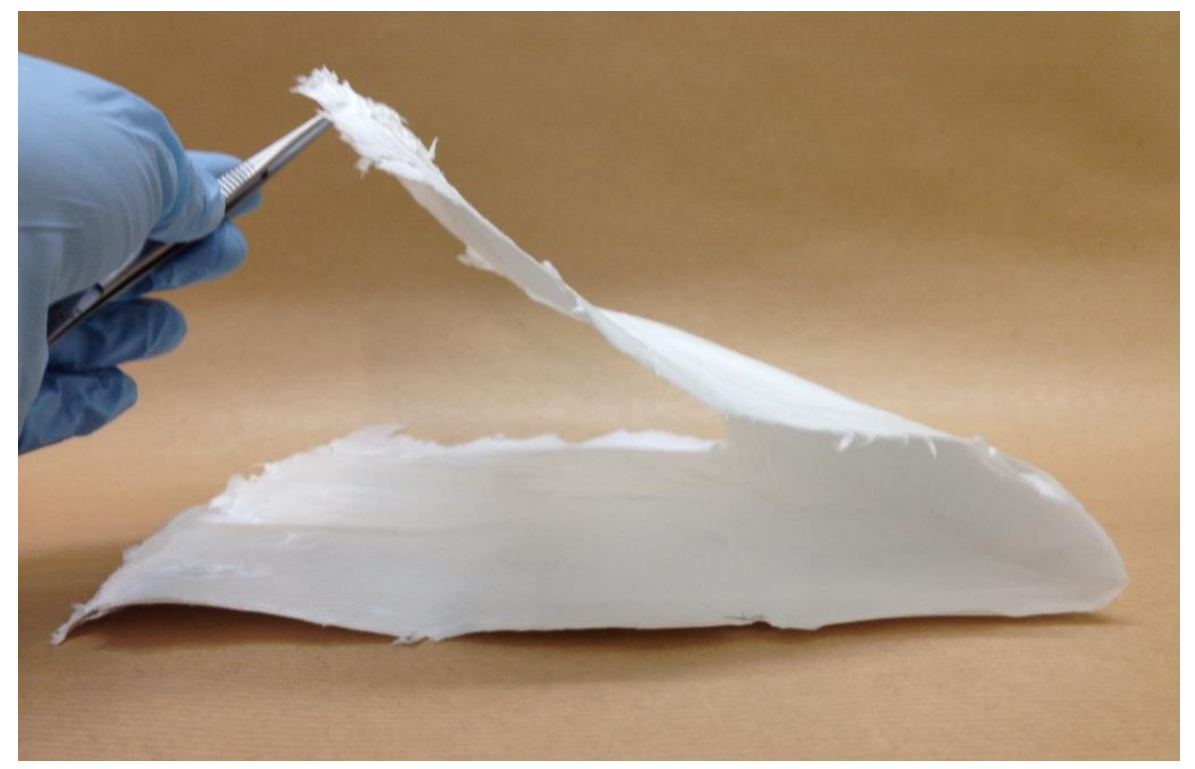

Figure 11: Picture of large $(30 \times 20 \mathrm{~cm})$ flexible silica nanofibrous sample

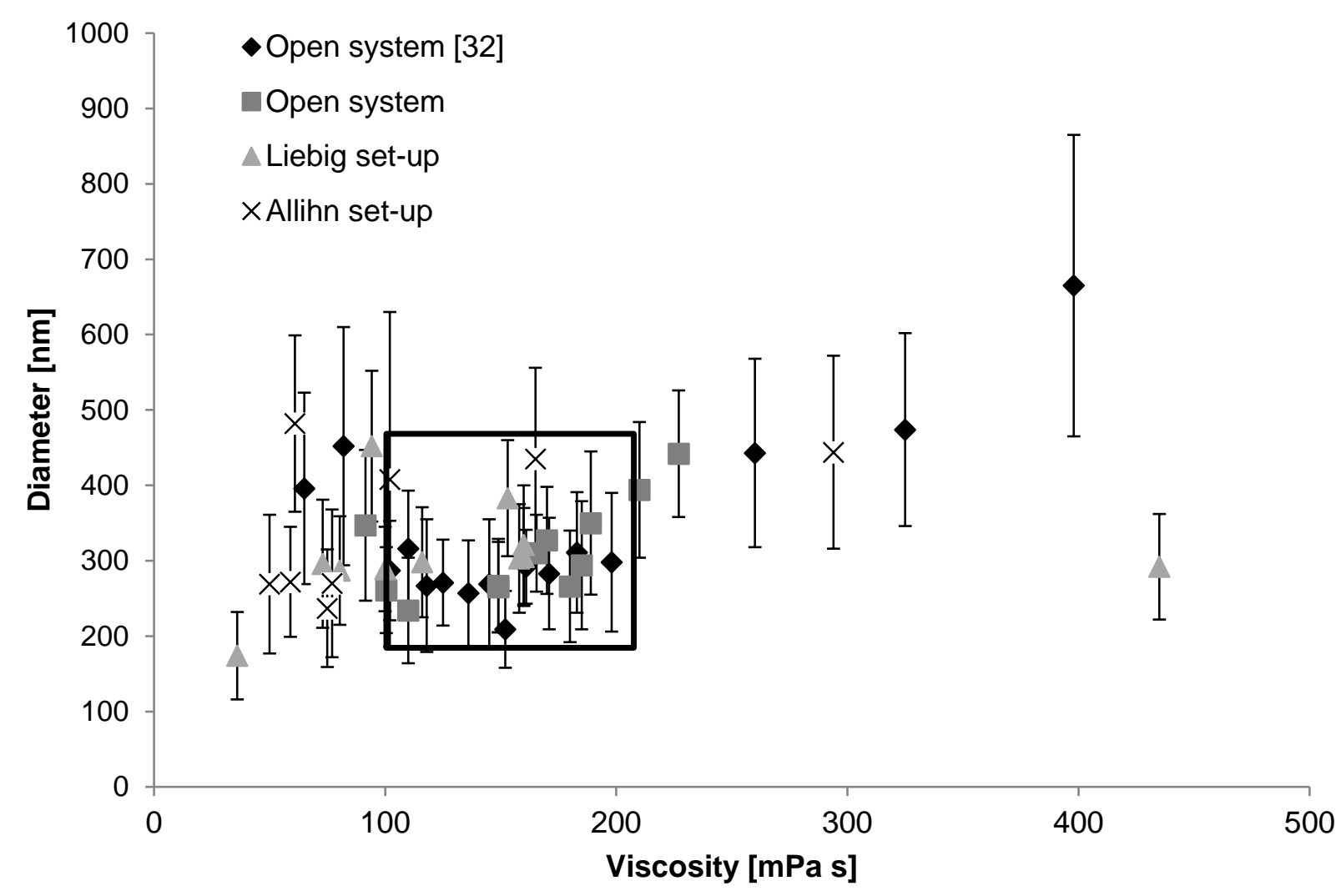

Figure 12: Nanofiber diameters as a function of the viscosity for sols prepared via the three set-ups, focus (frame) is given to the samples prepared in the stable viscosity region. 


\section{Conclusion}

The reproducibility of the tetraethoxysilane sols was confirmed for all systems via ATR-FTIR and ${ }^{29} \mathrm{Si} \mathrm{NMR}$. Additionally, it was possible to produce uniform nanofibers in a stable manner via the three different set-ups. Via the comparison of the three set-ups an in-depth characterization of the degree of crosslinking, concentration of ethanol and the sizes of colloidal species of the silica sols was performed. Moreover, the link was made with the viscosity of the sols. Furthermore, these results were linked with the electrospinning stability of the different sols and with the stability in time of the nanofibers. All of the parameters showed to have an influence on the electrospinning process and on the resulting nanofibers. Starting from a viscosity of $50 \mathrm{mPa}$ s nanofibers could be obtained, however the optimum viscosity stays in between 100 and $200 \mathrm{mPa}$ s for all sols. A concentration of ethanol of $9 \mathrm{~mol} \mathrm{~L}^{-1}$ in the sols seemed to be optimal for electrospinning. Additionally, the degree of crosslinking and the particle size have an important influence on the stability of the electrospinning process. Moreover, both parameters seem to be related. The most stable electrospinning processes are achieved when the particles are small $(<3.5 \mathrm{~nm})$ and a high amount of $\mathrm{Q}^{2}$ species is available. With increasing particle sizes and increasing crosslinking (thus decreasing $\mathrm{Q}^{2}$ species) electrospinning becomes less stable. However, a certain degree of crosslinking and size of colloidal particles is necessary to obtain no further crosslinking of the nanofibers after deposition. As a consequence, an optimum degree of crosslinking and particle size (3.5-7 nm) exists resulting in a stable electrospinning process and uniform, beadless nanofibers which stay stable in time. Further increasing the viscosity and particle sizes resulted in less stable electrospinning behavior. In conclusion, via all three set-ups uniform and beadless nanofibers could be obtained, having the same trends in nanofiber diameters as well when all parameters are in the appropriate limit. Moreover, successful up scaling resulted in the production of larger, flexible silica nanofibrous membranes. 


\section{References}

[1] Dai, Y., Liu, W., Formo, E., Sun, Y. and Xia, Y. Ceramic nanofibers fabricated by electrospinning and their applications in catalysis, environmental science and energy technology. Polymers Advanced Technologies. 2011, 22 326-338

[2] Sigmund, W., Yuh, J., Park, H., Maneeratana, V., Pyrgiotakis, G., Daga, A., Taylor, J., Nino, $\mathrm{J}$. Processing and structure relationships in electrospinning of ceramic fiber systems. Journal of the American Ceramic Society. 2006, 89 (2) 395-407

[3] Li, D., McCann, J., Xia, Y., Marquez, M. Electrospinning: a simple and versatile technique for producing ceramic nanofibers and nanotubes. Journal of the American Ceramic Society. 2006 89 (6) $1861-1869$

[4] Ramaseshan, R., Sundarrajan, S., Jose, R., Ramakrishna, S. Nanostructured ceramics by electrospinning. Journal of Applied Physics. 2007, 102111101

[5] Cavaliere, S., Subianto, S., Savych, I., Jones, D. J., Rozière, J. Electrospinning: designed architectures for energy conversion and storage devices. Energy and Environmental Science 4 (2011), 4761-4785

[6] Du, P., Song, L., Xiong, J., Cui, C. Optimization of electrospun $\mathrm{TiO}_{2}$ nanofibers photoanode film for dye-sensitized solar cells through interfacial pretreatment, controllable calcination, and surface post-treatment. Surface and Interface Analysis, 2013, 45, 1878-1883

[7] Wang, X., Fan, H., Ren, P., Yu, H., Li, J. A simple route to disperse silver nanoparticles on the surface of silica nanofibers with excellent photocatalytic properties. Materials Research Bulletin 47 (2012) 1734-1739

[8] Irani, M., Keshtkar, A.R., Moosavian, M.A. Removal of cadmium from aqueous solotiun using mesoporous PVA/TEOS/APTES composite nanofibers prepared by sol-gel electrospinning. Chemical Engineering Journal 200-202 (2012) 192-201

[9] Wu, S., Li, F., Wu, Y., Xu, R., Li, G. Preparation of novel poly(vinyl alcohol)/SiO $\mathrm{S}_{2}$ composite nanofiber membranes with mesostructure and their application for removal of $\mathrm{Cu}^{2+}$ from waste water. Chemical Communications 46 (2010) 1694-1696

[10] Ma, Z., Ji, H., Teng, Y., Dong, G., Zhou, J., Tan, D., Qiu, J. Engineering and optimization of nano- and mesoporous silica fibers using sol-gel and electrospinning techniques for sorption of heavy metal ions. Journal of Colloid and Interface Science 358 (2011) 547-553

[11] Sundarrajan, S., Chandrasekaran, A.R., Ramakrishna, S. An update on nanomaterials-based textiles for protection and decontamination. Journal of the American Ceramic Society (2010) 93 (12) $3955-3975$ 
[12] Ramakrishna, S., Fujihara, K., Teo, W.-E., Yong, T., Ma, Z., Ramaseshan, R. Electrospun nanofibers: solving global issues. Review feature. Materials Today. 2006, volume 9, number 3, $40-50$

[13] Ramakrishna. An introduction to electrospinning of nanofibers

[14] Agarwal, Greiner, Wendorff. Electrospinning: Materials, Processing and Applications.

[15] Li, D. Xia, Y. Electrospinning of nanofibers: reinventing the wheel. Advanced Materials. 2004, 16, No. 14, July 19

[16] Greiner, A., Wendorff, J. Electrospinning: A fascinating method for the preparation of ultrathin fibers. Angewandte Chemie International Edition. 2007. 46, 5670-5703

[17] De Schoenmaker, B., Goethals, A., Van der Schueren, L., Rahier, H., De Clerck, K. Polyamide 6.9 nanofibres electrospun under steady state conditions from a solvent/non-solvent solution. Journal of Materials Science. 2012, 47:4118-4126

[18] De Vrieze, S., De Schoenmaker, B., Ceylan, O., Depuydt, J., Van Landuyt, L., Rahier, H., Van Assche, G., De Clerck, K. Morphologic study of steady state electrospun polyamide 6 nanofibres. Journal of Applied Polymer Science. 2011, 119, 5, 2984-2990

[19] Van der Schueren, L., De Schoenmaker, B., Kalaoglu, Ö., De Clerck, K. An alternative solvent system for the steady state electrospinning of polycaprolactone. European Polymer Journal, 2011, 47, 6, 1256-1263

[20] Brinker, Scherer. Sol-Gel Science. The physics and Chemistry of Sol-Gel Processing.

[21] Carter, C.B., Norton, M.G. Ceramic materials, Science and Engineering

[22] Mahltig, B., Textor, T. Nanosols and textiles

[23] Choi, S.-S., Lee, S.G., Im, S.S., Kim, S.G., Joo, Y.L. Silica nanofibers from electrospinning/sol-gel process. Journal of Materials Science Letters 22 (2003) 891-893

[24] Choi, S.-S., Chu, B., Lee, S.G., Lee, S.W., Im, S.S., Kim, S.H., Park, J.K. Titania-doped silica fibers prepared by electrospinning and sol-gel process. Journal of Sol-Gel Science and Technology 30 (2004) 215-221

[25] Toskas, G., Cherif, C., Hund, R.-D., Laourine, E., Mahltig, B., Fahmi, A., Heinemann, C., Hanke, T. Chitosan(PEO)/silica hybrid nanofibers as a potential material for bone regeneration

[26] Li, D., Xia, Y. Electrospinning of polymeric and ceramic nanofibers as uniaxially aligned arrays. Nano Letters, 2003, 3, 555 
[27] Li, D., Xia, Y. Direct fabrication of composite and ceramic hollow nanofibers by electrospinning. Nano letters, 2004, 3, 933

[28] Azad, A.-M. Fabrication of transparent alumina (A12O3) nanofibers by electrospinning. Materials Science and Engineering A, 435-436 (2006), 468-473

[29] Formo, E., Camargo, P.H.C., Lim, B., Jiang, M.J., Xia, Y.N. Functionalization of ZrO2 nanofibers with Pt nanostructures: The effect of surface roughness on nucleation mechanism and morphology control. Chemical Physics Letters 476 (2009) 56-61

[30] Formo, E. Yavuz, M.S., Lee, E.P., Lane, L., Xia, Y.N. Functionalization of electrospun ceramic nanofiber membranes with noble-metal nanostructures for catalytic applications. Journal of Materials Chemistry, 19 (2009), 3878-3882

[31] Lee, S.X., Kim, Y.U., Choi, S.S., Park, T.Y., Joo, Y.L. Preparation of SiO2/TiO2 composite fibers by sol-gel reaction and electrospinning. Materials Letters. Volume 61, issue 3 (2007) 889893

[32] Geltmeyer, J. Van der Schueren, L., Goethals, F., De Buysser, K., De Clerck, K. Optimum sol viscosity for stable electrospinning of silica nanofibers. Journal of sol-gel science and technology. Volume 67, issue 1 (2013) 188-195

[33] Brinker, C.J., Assink, R.A. Spinnability of silica sols: structural and rheological criteria. Journal of Non-Crystalline Solids 111 (1989) 48-54

[34] Sakka, S., Yoko, T. Fibers from gels. Journal of Non-Crystalline Solids 147-148 (1988) $142-153$

[35] Sakka, S., Kozuka, H. Rheology of sols and fiber drawing. Journal of Non-Crystalline Solids 100 (1988) 142-153

[36] Pouxviel, J.C., Boilot, J.P. NMR study of the sol/gel polymerization. Journal of NonCrystalline Solids 89 (1987) 345-360

[37] Depla, A., Verheyen, E., Veyfeyken, A., Van Houteghem, M., Houthoofd, K., Van Speybroeck, V., Waroquier, M., Kirschhock, C., Martens, J. UV-Raman and ${ }^{29} \mathrm{Si}$ NMR spectroscopy investigation of the nature of silicate oligomers formed by acid catalyzed hydrolysis and polycondensation of tetramethylorthosilicate. The journal of physical chemistry. 115 (2011) 11077-11088.

[38] Depla, A., Lesthaeghe, D., van Erp, T.S., Aerts, A., Houthoofd, K., Fan, F., Li, C., Van Speybroeck, V., Waroquier, M., Kirschhock, C., Martens, J. ${ }^{29} \mathrm{Si}$ NMR and UV-Raman investigation of initial oligomerization reaction pathways in acid-catalyzed silica sol-gel chemistry. The journal of physical chemistry. 115 (2011) 3562-3571 
[39] Malay, O., Yilgor, I., Menceloglu, Y. Effect of solvent on TEOS hydrolysis kinetics and silica particle size under basic conditions. Journal of sol-gel science and technology. 67 (2013) 351-361

[40] Sadisivan, S., Dubey, A. K., Li, Y., Rasmussen, D.H. Alcoholic solvent effect on silica synthesis - NMR and DLS investigation. Journal of sol-gel science and technology. 12 (1998) 514

[41] Brian Smith. Infrared spectral interpretation: A systematic approach. 1999 ISBN 0-84932463-7

[42] Pirzada, T. Arvidson, S.A., Saquing, C.D., Shah, S.S., Khan, S.A. Hybrid silica-PVA nanofibers via sol-gel electrospinning. Langmuir. 28 (2012) 5834-5844

[43] Innocenzi, P. Infrared spectroscopy of sol-gel derived silica-based films: a spectramicrostructure overview. Journal of non-crystalline solids. 316 (2003) 309-319

[44] McCormick A.V., Bell, A.T., Radke C.J. Quantitative determination of siliceous species in sodium silicate solutions by ${ }^{29} \mathrm{Si}$ NMR spectroscopy. Zeolites 7 (1987) 183

[45] Schwarz, J., Contescu, X. Surfaces of nanoparticles and porous materials. 1999

[46] Bahlmann, E., Harris, R., Say, B. Method for the quantification of silicon-29 NMR spectra, developed for viscous silicate solutions. Magnetic Resonance in chemistry, 31 (1993) 266-267

[47] Ralph K. Iler, The Chemistry of silica - Solubility, polymerization, colloid and surface properties and biochemistry- ISBN 0-471-02404-X.

[48] He, J.-H, Liu, Y., Mo, L.-F., Wan, Y.-Q., Xu, L. Electrospun nanofibers and their applications. Smithers, 2008. 